\title{
MOBILIDADES QUALIFICADAS E EMPREENDEDORAS NO CONTEXTO DOS MOVIMENTOS MIGRATÓRIOS CONTEMPORÂNEOS E DA CRISE ECONÓMICA
}

\author{
Maria da Conceição Pereira Ramos ${ }^{1}$
}

\section{RESUMO}

Os movimentos migratórios contemporâneos apresentam maior complexidade que no passado, em consequência da diversidade crescente de fluxos, destinos, intensidades, temporalidades e impactos a diferentes níveis. Assistimos à acelerada internacionalização da educação e do trabalho, mas também, no contexto da globalização e da sociedade de informação e do conhecimento, à procura crescente de pessoal altamente qualificado em determinados setores. Podemos identificar novas tendências nos fluxos migratórios, nomeadamente ao nível do acréscimo da migração juvenil, qualificada e feminina, aumento da mobilidade no espaço europeu e procura de destinos fora da Europa, fenómeno ampliado pelo ciclo económico recessivo, facilidade de circulação internacional, exigência de maiores competências, políticas migratórias e de cooperação entre países de origem e de destino. Esta mobilidade tem-se acentuado, por iniciativa individual ou do empregador, com o aumento do desemprego e da oferta de jovens diplomados, a procura de maior formação e desenvolvimento internacional da carreira, novas experiências e desafios profissionais e o aumento do trabalho feminino na economia global e em setores específicos, como o da educação e da saúde. Procuraremos analisar as migrações internacionais qualificadas e empreendedoras, de homens e mulheres, de jovens, tendência à escala global, mas também em Portugal, particularidades, desafios, oportunidades e impactos deste fenómeno no conhecimento, mercado de trabalho, desenvolvimento e transferência de competências, nas dinâmicas de empreendedorismo e inovação em contexto de crise económica. A internacionalização económica, científica e cultural exige a gestão de competências e da interculturalidade, face ao aumento da mobilidade humana, e novos paradigmas das migrações apelam à cooperação e ao fortalecimento do codesenvolvimento entre países de imigração e de emigração.

Palavras-chaves: Migrações Qualificadas; Feminização das Migrações; Mobilidade Juvenil, Formação e Carreira; Empreendedorismo Migrante; Migrações em Portugal.

\footnotetext{
${ }^{1}$ Professora da Universidade do Porto (FEP) e investigadora do CEMRI. E-mail: cramos@fep.up.pt
} 


\begin{abstract}
Contemporary migration have increased complexity of the growing diversity of flows, locations, intensities, temporality, and the impacts at different levels. He witnessed the accelerated internationalization of education and work, but also in the context of globalization and the information society and knowledge, the increasing demand for highly qualified personnel in certain sectors. We can identify new trends in migration flows, particularly in the growth of young and female skilled migration, increased mobility in Europe and demand for destinations outside Europe, a phenomenon amplified by the economic downturn, ease international movement, which require greater skill level, migration policies and cooperation between countries of origin and destination. This mobility has been accentuated by the employer or individual initiative, with rising unemployment and the supply of graduates, the demand for greater international training and professional development, new experiences and professional challenges, and increased female labor in general and in specific sectors such as the economics of education and health. Try to analyze international migration and skilled entrepreneurs, men and women, young, trend globally, but also in Portugal, specificities, challenges, opportunities and implications of this phenomenon in the knowledge, labor market development and transfer skills, dynamic entrepreneurship and innovation in the context of the economic crisis. Economic, scientific and cultural internationalization requires skills and intercultural management, due to increased human mobility, and new paradigms of migration I do to strengthen cooperation and development between the countries of immigration and emigration.
\end{abstract}

Keywords: Qualified Migration. Feminization of Migration. Youth Mobility. Training and Career. Migrant Entrepreneurship. Migration in Portugal. 


\section{Introdução}

A migração internacional constitui uma experiência humana abrangente e um processo de transformação das estruturas fundamentais e das instituições das sociedades que surgem através de mudanças globais e relações políticas, económicas e sociais (Castles, 2010). A crescente globalização veio alterar o contexto das migrações e é inegável que os processos de mobilidade têm conhecido acelerações espetaculares que os transformam qualitativamente (Ramos, 2013). A migração internacional está muito relacionada com a situação económica dos países envolvidos, sendo este um dos principais fatores que estimula as pessoas a saírem do seu país de origem. A emigração dos países em crise da Europa do Sul progrediu 45\% entre 2009 e 2011 (OECD, 2013). Contudo, se os fatores específicos ligados ao país de origem têm um papel determinante na dinâmica dos fluxos migratórios e na sua estruturação sociodemográfica, são as realidades socioeconómicas do país de destino que decidem as condições e as modalidades de inserção económica das populações imigrantes. A chamada motivação económica está muitas vezes combinada com outros fatores denominados "não-económicos" associados às motivações individuais que determinam a decisão de emigrar (Fracalossi e Ramos, 2013).

\section{Internacionalização do trabalho qualificado e da educação}

Um fator de atração induzido pela mundialização diz respeito à mão-de-obra qualificada e ao empreendedorismo transnacional, sendo o aumento da emigração dos mais qualificados, homens e mulheres, e a sua maior procura ao nível mundial, uma tendência dos últimos anos (Ramos, 2008, 2013; Chiswick, 2011). A utilização de estratégias enquadradas na globalização e o rápido crescimento económico entre as nações mais desenvolvidas foram importantes catalisadores para a mudança de paradigma ao nível da 
gestão de recursos humanos, verificando-se uma procura exacerbada por trabalhadores internacionais de elevado capital humano (Meyskens et al., 2009). O contexto de internacionalização dos mercados de trabalho, o incremento da ciência e inovação e a cooperação com os países de emigração exigem atenção acrescida à gestão da educação, de competências e da interculturalidade, face ao aumento dos migrantes altamente qualificados e da mobilidade estudantil internacional (Ramos, 2011b; Robertson, 2013; Ramos, 2014).

O brain drain, ou "êxodo de competências" para os países desenvolvidos, é um fenómeno crescente que afeta sobretudo os países mais pobres. Nos países da Organização para a Cooperação e o Desenvolvimento Económico (OCDE), as migrações com fins de emprego qualificado representam uma parte crescente da mobilidade internacional: pessoal associado às novas tecnologias, à saúde e educação, aumento de estudantes estrangeiros, nomeadamente na Europa, tendência à "fuga de cérebros", tendo o género feminino sido subestimado (Dumont, Martin e Spielvogel, 2007). As migrações de pessoal de saúde, médicos e enfermeiros intensificaram-se na última década, na maior parte dos países desenvolvidos (EUA, Canadá, Reino Unido, França, Suíça, Irlanda, entre outros), face à procura de cuidados de saúde, ao envelhecimento da população e à degradação das condições económicas dos países de origem dos migrantes, originários sobretudo de África e da Ásia (OCDE, 2010; Grignon et al., 2012; Ramos, Deaconu, Radu, 2013).

Os países desenvolvidos da União Europeia e da OCDE têm tomado medidas para atrair e facilitar o recrutamento de trabalhadores estrangeiros qualificados e altamente qualificados (OCDE, 2008; Kahanec, 2012). Representando os estudantes estrangeiros móveis um potencial de capital humano qualificado importante, tem havido esforços dos países no que respeita à 
equivalência dos diplomas, desenvolvimento de programas de mobilidade internacional com bolsas, procurando-se implementar um espaço europeu de educação e de investigação e facilitar a mobilidade e inserção no mercado de trabalho europeu e global. Nas universidades portuguesas, o número de alunos estrangeiros tem vindo a crescer, sendo a grande maioria de origem brasileira, dos PALOP (Países Africanos de Língua Oficial Portuguesa), mas também espanhola e italiana, fortemente representada no programa europeu Erasmus. O Erasmus Mundus, criado em 2004, promove a mobilidade entre estudantes da União Europeia (UE) e países não europeus, sendo a Universidade do Porto uma das universidades europeias que mais estudantes recebe e exporta ${ }^{2}$ no âmbito deste programa da UE para a cooperação e mobilidade no ensino superior com instituições de países exteriores à Europa, contribuindo desta forma para o desenvolvimento dos recursos humanos, empregabilidade e perspetivas de carreiras dos estudantes e para as capacidades de internacionalização das instituições envolvidas e respetivos sistemas de ensino, buscando o diálogo e compreensão intercultural recíprocos (Sobral e Ramos, 2012; Ramos, 2014).

Segundo o relatório de internacionalização da Universidade do Porto (UP) (2014), do ano letivo de 2012/2013, os estudantes e investigadores estrangeiros representaram $12,6 \%$ do total de estudantes desta universidade. Em 2013, a UP recebeu mais de 4 mil estudantes estrangeiros de 112 países. A procura de educação terciária internacional teve enorme crescimento nas últimas décadas e o número de estudantes estrangeiros em mobilidade internacional aumentou constantemente a partir do ano 2000, atingindo 3,6 milhões de estudantes móveis no mundo em $2010^{3}$. Os indicadores mostram a globalização do ensino superior em

\footnotetext{
${ }^{2}$ De acordo com a Comissão Europeia a Universidade do Porto foi a $24^{\mathrm{a}}$ universidade europeia mais procurada pelos estudantes estrangeiros que

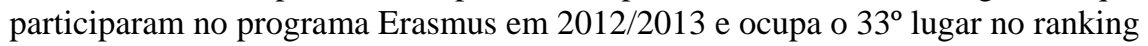
das universidades que mais estudantes "exportam" ao abrigo deste programa.

${ }^{3}$ Global Flow of Tertiary-level Students, UNESCO Institute of Statistics (UIS) in Canada, October 2012.
} 
várias regiões do mundo, tendência que irá continuar a acentuar-se nos próximos anos, esperando-se que em 2025 os estudantes em programas de mobilidade internacional atinjam os 8 milhões anuais ${ }^{4}$. EUA, Reino Unido, Alemanha, França e Austrália são os principais países de destino destes estudantes (OECD, 2012). Cerca de 15 a $30 \%$ dos estudantes internacionais ficam no país dos seus estudos, seja por razões familiares/casamento com um residente, seja por razões profissionais (OECD, 2011). Utilizando dados para 78 países de origem, Dreher e Potvaara (2005) examinaram o impacto dos fluxos de estudantes para os EUA sobre a migração posterior ao longo do período 1971-2001 e concluíram que o stock de estudantes estrangeiros é um importante preditor de migração subsequente.

O programa INOV Contacto da AICEP Portugal Global, oferece estágios profissionais internacionais, de seis a nove meses, para jovens quadros até aos 30 anos, com qualificação superior. 32\% dos jovens são recrutados posteriormente para trabalhar nas empresas onde estagiam. Gestão e Engenharia predominam entre as áreas dos estagiários selecionados, assim como os destinos do Brasil e Moçambique, existindo outros países de acolhimento importantes, como os EUA, China e Espanha.

\section{Emigração portuguesa e caracterização sociodemográfica}

A condição migrante marca a história e a identidade dos portugueses (Godinho, 1978). Os fluxos de saída aumentaram significativamente nos últimos anos, embora não existam números precisos quanto aos portugueses que emigraram com formação superior (licenciatura ou mais). Estimativas do Instituto Nacional de Estatística (INE) para emigrantes temporários e permanentes e informações da Secretaria de Estado para as Comunidades

\footnotetext{
${ }^{4}$ E. Gibney, A different world. THE, Times Higher Education, 31 January 2013, London.
} 
Portuguesas referem a saída anual entre 100 a 120 mil portugueses, em 2011, 2012 e 2013, essencialmente dos grandes centros urbanos, como Lisboa e Porto, estando os jovens qualificados fortemente representados. $\mathrm{Em}$ 2012, 21\% dos emigrantes permanentes ${ }^{5}$ tinham idades entre $25-29$ anos e $17 \%$ dos emigrantes temporários ${ }^{6}$ estavam na faixa etária dos 20-24 anos (INE).

Ainda de acordo com o INE (Estatísticas do Emprego), a taxa de desemprego dos jovens portugueses com menos de 25 anos atingiu 38\% em 2012 e 2013. O número de desempregados com o ensino superior passou de 127.400 para 142.400 entre 2012 e 2013. Cerca de $20 \%$ dos licenciados portugueses emigram (Docquier e Marfouk, 2006). O desemprego destes diplomados contribui para acentuar o brain drain. No Brasil, as autorizações de trabalho concedidas aos portugueses apresentaram um percentual de aumento de $121 \%$ entre 2009 e 2011, segundo dados do Ministério do Trabalho e Emprego do Brasil. A maioria dos imigrantes que solicitaram autorização de trabalho neste país tem o ensino superior completo ou habilitação legal equivalente.

Uma grande parte da emigração portuguesa ocorre no espaço da livre circulação da União Europeia e dirige-se para grandes metrópoles onde há procura de mão-de-obra qualificada, como no Reino Unido, Alemanha, França e Suíça, mas também para novos destinos extraeuropeus em economias emergentes, como o Brasil e Angola. Enfermeiros, farmacêuticos e médicos dentistas têm na Europa o destino privilegiado, particularmente no Reino Unido, onde parte significativa dos portugueses tem o ensino superior (Ramos, Deaconu, Radu, 2013). No Luxemburgo, país de forte concentração de portugueses, uma pequena percentagem destes está entre os mais qualificados, no setor financeiro e na atividade

\footnotetext{
${ }^{5}$ Intenção de permanecer noutro país por um período igual ou superior a um ano.

${ }^{6}$ Intenção de permanecer noutro país por um período inferior a um ano.
} 
científica. Engenheiros, arquitetos, gestores, face à recessão do setor da construção em Portugal, emigram para destinos mais distantes, na América do Sul, como o Brasil, e em África, nomeadamente Angola e Moçambique, onde a oferta de emprego tem crescido (Costa, 2009; Fracalossi e Ramos, 2013). Nos últimos anos, de entre os principais países fornecedores de remessas de emigrantes para Portugal, além dos tradicionais, França e Suíça, Angola surge a seguir em termos de importância, atestando esta nova realidade e representando a quase totalidade das remessas oriundas dos PALOP (Banco de Portugal). O aumento não é tão significativo para o Brasil, sobretudo devido à falta de equivalências e reconhecimento de diplomas para certas profissões, como engenheiros e arquitetos, dificultando o exercício naquele país.

Se, no passado, eram principalmente os homens portugueses que emigravam, ao longo do tempo, esta situação tem vindo a alterar-se (Ramos, 2009, 2011a), mas não completamente, pois a emigração temporária e permanente, em 2011 e 2012, era, segundo os dados do INE, ainda predominantemente masculina: em 2011, 30\% dos emigrantes temporários eram mulheres e em 2012, 34\% dos emigrantes permanentes pertenciam ao sexo feminino.

As autoridades portuguesas pretendem continuar a atrair fluxos que aumentaram nos últimos anos, como estudantes estrangeiros e reformados, captar imigrantes qualificados e com potencial, residentes de longa duração, emigrantes portugueses e evitar a saída de jovens, nomeadamente qualificados. Um inquérito aos investigadores portugueses bolseiros de diferentes áreas, realizado pela Associação de Combate à Precariedade Laboral, com base em mais de 1800 respostas, constata que trabalham precariamente (77,8\% nunca tiveram contrato) e a maioria pretende emigrar (apenas 21,5\% dos entrevistados rejeitam a hipótese de o fazer). 


\section{Empreendedorismo migrante, género e desenvolvimento}

Os imigrantes contribuem para o desenvolvimento dos países de acolhimento, com novos conhecimentos e competências e reduzindo a escassez de trabalho. A sua participação económica através da criação de novos negócios tem merecido uma atenção limitada, apesar destes terem vindo a aumentar progressivamente na última década, em vários setores e profissões, contribuindo para a criação de emprego. Os imigrantes são um pouco mais empreendedores do que os nativos em quase todos os países da OCDE e criam novos negócios e empresas, embora a taxa de sobrevivência destas seja muitas vezes menor (OECD, 2010). Esta evolução do empreendedorismo é em parte resultado do crescente nível de escolaridade dos imigrantes, mas também das mudanças na estrutura da economia pós-industrial (Kloosterman e Rath, 2010).

O contributo dos imigrantes para o empreendedorismo e a criação de emprego, o seu impacto no crescimento económico e no mercado de trabalho dos países de acolhimento de alguns países da OCDE é analisado na obra Open for business. Migrant entrepreneurship in OECD Countries (OECD, 2010), onde são discutidas opções políticas para promover o desenvolvimento e o sucesso das iniciativas dos migrantes. Esta obra analisa os fatores determinantes do empreendedorismo migrante em Portugal e na Suíça, a experiência de certos países nesta matéria (França, Reino Unido, Canadá, EUA), o empreendedorismo de mulheres migrantes, os contributos dos empreendedores migrantes para a inovação e a expansão do comércio internacional, as dificuldades dos migrantes na criação e desenvolvimento dos seus negócios (em França e EUA) e a necessidade de melhorar o acesso ao crédito por parte das empresas dos migrantes.

Ao investigar o desenvolvimento do empreendedorismo entre quatro grupos de imigrantes nos EUA - hispânicos, chineses, turcos e polacos - Panayiotopoulos (2010) explora a sua 
contribuição para o mundo empresarial. Estes empreendedores imigrantes, longe de tirarem o trabalho aos cidadãos dos países de acolhimento, criam grande número de empregos em diferentes setores, desde os restaurantes étnicos até às grandes empresas de tecnologias de informação. Frequentemente, os empreendedores começam como trabalhadores por conta de outrem e, para enfrentar a crise, recorrem ao auto emprego e à criação de pequenas empresas como estratégia de sobrevivência e de integração na economia do país de acolhimento (Panayiotopoulos, 2010).

Um dos obstáculos à atividade empresarial é a dificuldade de acesso ao crédito, pelo qual muitos imigrantes não conseguem responder aos requisitos exigidos pelos bancos. Os apoios e oportunidades ao empreendedorismo imigrante têm-se multiplicado nos últimos anos, sob responsabilidade de associações não lucrativas, da banca e do próprio Estado, e um exemplo é o microcrédito, uma política social ativa de finanças solidárias que representa uma pequena quantia de dinheiro emprestada a pessoas com poucos recursos para estimular as suas capacidades empreendedoras e promover a criação de emprego. A inclusão social, através do microempreendedorismo, é um dos grandes objetivos do microcrédito, ajudando estas iniciativas empresariais a melhorar as condições de vida e de trabalho dos imigrantes no país de acolhimento.

Nos investimentos imigrantes resultantes de microcrédito em Portugal, a taxa de sucesso é elevada, existindo frequentes casos de expansão das atividades iniciais, de que são beneficiários nomeadamente imigrantes de África e da América, sobretudo do Brasil, segundo dados da Associação Nacional de Direito ao Crédito (ANDC).

As práticas de empreendedorismo feminino migrante têm merecido pouca atenção na literatura académica, acentuando-se só mais recentemente (Brettell, 2007; Ramos, 2010; Korpi et al., 2013). No 
contexto de feminização das migrações, verifica-se o papel ativo das mulheres como agentes económicos e de desenvolvimento nos países de origem e de acolhimento, o seu empreendedorismo social e a manutenção de espaços familiares transnacionais. Para além das transferências financeiras, fundamentais para os países de emigração, como Portugal, as/os migrantes efetuam para o país de origem transferências "invisíveis" e "remessas sociais" (Levitt, 1998): comportamentos económicos, saberes e saber-fazer, trocas sociais e culturais que envolvem ideias, práticas, identidades e capital social que o imigrante traz consigo e desenvolve dentro da família e da comunidade nos locais de origem, contribuindo para mudanças progressistas que afetam mentalidades, hábitos de vida, educação, participação cívica, igualdade entre os géneros e aumento da coesão social (Ramos, 2011a).

O empreendedorismo social das mulheres portuguesas migrantes é visível na sua participação em associações de imigrantes, em associações cívicas ou em organizações políticas, nestas, contudo, ainda com participação baixa (Ramos, 2009, 2012a). No movimento associativo português emigrante, as novas gerações de mulheres evidenciam-se na liderança e dinamização de atividades culturais e recreativas, mas também no controlo da gestão e no associativismo empresarial e político (Ramos, 2012b). O empreendedorismo propicia a dinamização de redes e práticas de inovação social com impactos que ultrapassam o grupo imigrante e abarcam o empreendedorismo económico, associativo, cultural e político.

Segundo um estudo sobre o empreendedorismo das mulheres imigrantes em Portugal (Malheiros e Padilha, 2010), estas são menos empreendedoras e apresentam mais dificuldades do que os homens, investindo geralmente em iniciativas empresariais de pequena ou muito pequena dimensão. Para se tornarem empreendedoras, $65,5 \%$ das imigrantes inquiridas utilizaram as 
suas poupanças. As iniciativas empresariais por parte dos migrantes são influenciadas por diversos fatores e oportunidades: estatuto legal, tempo de permanência no país de acolhimento, experiência profissional e nível de instrução, etc. (Kloostermann e Rath, 2010). Podemos encontrar imigrantes com percursos escolares, científicos, artísticos e de empreendedorismo económico e social, com ascensão através da formação, qualificação e reconhecimento do seu trabalho. $\mathrm{O}$ empreendedorismo feminino também pode resultar da necessidade de conciliação entre a vida pessoal, familiar e a vertente económica. Muitas vezes, a alternativa a um emprego por conta de outrem com horários incompatíveis com a gestão da vida familiar condiciona a mulher para o autoemprego ou para situações conceptualizáveis como de empreendedorismo. Este pode assim melhorar a qualidade de vida dos imigrantes e das suas famílias e constituir uma estratégia de sobrevivência na luta contra o desemprego e a exclusão (Abada, Hou, Lu, 2014).

Dada a importância da integração dos imigrantes nos países de acolhimento e a significativa contribuição para as economias desses países, o empreendedorismo migrante faz parte das preocupações políticas dos Estados Membros da União Europeia e da OCDE. O número crescente de estudos científicos e programas sobre este empreendedorismo e o aumento dos negócios étnicos mostram a importância desta realidade. As diásporas são um motor de desenvolvimento e de aproximação de comunidades, sendo responsáveis pela introdução nos países de origem de novas ideias, pela aceleração do processo de internacionalização, pela facilitação de contactos e pela criação de redes de confiança e proximidade. Promovido pela Fundação Calouste Gulbenkian (FCG), desde 2010, o objetivo da iniciativa FAZ - Ideias de origem portuguesa é apoiar projetos de empreendedorismo social, desenvolvidos por cidadãos portugueses na diáspora, nas áreas do ambiente e sustentabilidade, inclusão social, diálogo cultural e envelhecimento. A iniciativa FAZ, também promovida pela Cotec 
Portugal, reúne o concurso Ideias de origem portuguesa "Lá se pensam, cá se fazem" (FCG) e o Prémio Empreendedorismo Inovador na Diáspora Portuguesa (Cotec). Devido ao FAZ já regressaram a Portugal jovens portugueses, contrariando assim um movimento inverso de migração duma geração altamente qualificada.

Portugal procura atrair investimento estrangeiro através da atribuição de vistos gold, no âmbito do programa de autorização de residência para atividade de investimento - ARI (como fazem igualmente a Espanha, Itália e Malta). Desde outubro de 2012, início do programa de atribuição de vistos a estrangeiros que invistam 500 mil euros ou mais em imobiliário - ou um montante igual ou superior a um milhão de euros na transferência de capitais e na criação de, pelo menos, 10 postos de trabalho -, foram atribuídos por Portugal mais de 1000 vistos golds, maioritariamente a chineses, seguindo-se de longe as nacionalidades russa e brasileira, tendo a esmagadora maioria (cerca de 90\%) investido em imobiliário (Serviço de Estrangeiros e Fronteiras, SEF).

\section{Migrações qualificadas femininas no mercado de trabalho global}

É preciso salientar a complexidade e especificidade das experiências das mulheres migrantes, fenómeno que as ciências humanas apenas no último meio século têm procurado conhecer (Kofman, 2000; Ramos, 2011a). Autores como Falquet et al. (2010) destacam a necessidade de introduzir a perspetiva de "género e geração", além da "classe e etnia", na compreensão das migrações, para superar a invisibilidade de certos fluxos e ter uma visão mais integral do fenómeno. As mulheres registam hoje, segundo estimativas das Nações Unidas, cerca de metade do total mundial de migrantes, sendo protagonistas ativas. A feminização tem-se acentuado na imigração em Portugal, muito especialmente 
na imigração brasileira (Ramos, 2007). As autorizações de residência concedidas às estrangeiras atingiram 49\% em 2011, o que indicia a intensificação da entrada de mulheres por motivos de trabalho ou de reagrupamento familiar.

É importante a idade e a situação familiar na escolha da mobilidade. Docquier et al. (2012) estudaram os padrões de emigração de mulheres e homens qualificados e concluíram que a disposição feminina para acompanhar o cônjuge é mais pronunciada do que em relação ao homem. Se a maioria dos estudos internacionais evidencia que os investigadores do sexo masculino são muito mais propensos a participar nos programas de mobilidade e a estudar ou trabalhar fora do país de origem, em Portugal, essa diferença entre sexos é bastante mais reduzida. A pesquisa efetuada com investigadores portugueses no estrangeiro encontrou uma percentagem ligeiramente superior de mulheres portuguesas móveis (52\%), sendo que $55 \%$ dos doutorandos no estrangeiro analisados são mulheres (Delicado e Alves, 2013). Estas tendem a ser mais jovens do que os seus colegas homens, são sobretudo mulheres solteiras e com menor propensão para ter filhos.

O estudo da inserção laboral, da mobilidade profissional e do contributo socioeconómico de mulheres migrantes altamente qualificadas constitui uma dimensão frequentemente negligenciada na análise dos fluxos migratórios (Dumont, Martin, Spielvogel, 2007). No entanto, os movimentos migratórios das mulheres têm aumentado consideravelmente e elas desempenham um papel importante em serviços altamente qualificados, como resultado de vários fatores: crescimento do reagrupamento familiar, alterações das estruturas económicas com a transição para economias pósindustriais, aumento do nível educacional feminino nos países de origem, etc. A internacionalização do trabalho feminino é uma característica da globalização e das transformações laborais, 
existindo uma procura de trabalho feminino na economia global (novas tecnologias, saúde, educação, serviços pessoais e sociais) (Ramos, 2008, 2010). As mulheres migrantes integram-se nalguns setores de serviços em expansão e menos sensíveis aos ciclos conjunturais (Ramos, 2009, 2011a), e é possível que tenham aumentado a sua participação no mercado de trabalho, a fim de compensar as perdas de rendimentos dos homens imigrantes (OECD, 2011).

Tendo a migração feminina para países da OCDE aumentado significativamente nas últimas décadas, os stocks de migrantes são agora mais equilibrados relativamente ao género, o mesmo se verificando para os trabalhadores altamente especializados. As mulheres representavam, em média, $51 \%$ da população estrangeira total dos países da OCDE em 2000 (Dumont, Martin, Spielvogel, 2007). No Japão, Reino Unido e Itália, mais de 53\% dos imigrantes são mulheres. Segundo a taxa de emigração por escolaridade e sexo para 104 países (25 membros da OCDE e 79 países não membros da Organização) e as taxas de emigração altamente qualificada dos homens e das mulheres, estas são proporcionalmente mais propensas a emigrar. A taxa média de emigração de mulheres diplomadas do ensino superior é de 17,6\%, em comparação com 13,1\% para os homens. Tendo as mulheres um acesso desigual ao ensino superior, em muitos países menos desenvolvidos, elas estão sobre representadas na fuga de cérebros. Esta situação é reforçada pelo facto de a emigração de mulheres altamente qualificadas ser maior quanto mais pobre é o seu país de origem.

\section{Impactos da mobilidade internacional altamente qualificada na sociedade do conhecimento}

Com o crescimento do investimento direto estrangeiro (IDE), do comércio e da internacionalização da investigaçãodesenvolvimento (I\&D), a mobilidade de recursos humanos em 
ciência e tecnologia tornou-se um aspeto essencial da mundialização, abrangendo um número crescente de investigadores (Gaillard e Gaillard, 1999; Weinberg, 2011).

Diversos fatores contribuem para a mobilidade dos fluxos de trabalhadores altamente qualificados. Para além das incitações económicas, como maior remuneração, progressão de carreira e acesso a melhor financiamento da investigação, os talentos móveis procuram infraestruturas de investigação mais avançadas e oportunidades de trabalho com os melhores centros e especialistas (OCDE, 2008). As ligações familiares ou pessoais atraem igualmente os talentos para determinados destinos (Fracalossi e Ramos, 2013). As razões que levam, por exemplo, os estudantes a pretender formação superior num país estrangeiro são muito diversas: vão desde a procura de formação de qualidade internacionalmente reconhecida até à melhoria de perspetivas de trabalho futuro, passando, também, por motivações relacionadas com o reconhecimento social e as oportunidades de imigração (Ramos, 2014).

A mobilidade internacional qualificada tem impacto importante sobre a criação e difusão do saber. Para os países de acolhimento, o afluxo de talentos tem efeitos positivos no acréscimo da atividade económica e de I\&D, no aumento de fluxos de conhecimentos e de cooperação com os países de origem, no maior número de inscritos nos programas de estudos superiores e na criação potencial de empresas e empregos por empresários imigrantes (Enderwick, Tung, Chung, 2011). A mobilidade ajuda a associar as empresas nacionais ao saber estrangeiro e a estimular os efeitos de I\&D estrangeiro sobre as unidades locais de I\&D e o conjunto da economia.

Para os países de origem, os trabalhos sobre os efeitos da emigração focalizam-se essencialmente nas remessas dos migrantes e na fuga de cérebros, colocando o acento no impacto sobre os 
Países em Vias de Desenvolvimento (PVD), os quais produzem um número considerável de cientistas, mas experimentam uma forte fuga de cérebros. Os níveis de educação, população e PIB per capita estão positivamente relacionados com o número de cientistas importantes que nascem e ficam no país (Weinberg, 2011). As principais inquietações que geram a fuga de cérebros para os países de origem são a perda de mão-de-obra ativa e da produção correspondente, o custo da formação dos que emigram, e o impacto potencial sobre o desenvolvimento necessário das instituições, e a mudança estrutural. A emigração de trabalhadores qualificados, tal como de investigadores e cientistas, pode beneficiar a criação e difusão do saber no país de origem e encorajar o desenvolvimento de competências (Beine, Docquier, Rapoport, 2008).

A circulação dos recursos humanos qualificados estimula a transferência de conhecimentos para o país de origem, podendo significar o retorno dos emigrantes qualificados depois de um período no estrangeiro ou de uma migração temporária e circular entre país de origem e estrangeiro, sendo necessária a sua reintegração no mercado de trabalho de acordo com os seus conhecimentos e competências. Os maiores retornos são obtidos entre aqueles que depois de estudar no exterior voltam para o país de origem para trabalhar. A educação obtida no estrangeiro leva a um triplo ganho: para o país de acolhimento, para o país de origem e para os próprios (Poot e Roskruge, 2013). Os migrantes qualificados difundem no seu país de origem o saber adquirido e mantêm redes, facilitando a troca contínua de conhecimentos.

\section{Importância das migrações qualificadas juvenis na crise económica atual}

A emigração de jovens qualificados portugueses tem sido em massa nalgumas profissões da saúde, como nos enfermeiros, realidade evidenciada pelos pedidos recebidos pela Ordem dos 
Enfermeiros para reconhecimento das qualificações, requisito do processo de mobilidade internacional. As estimativas indicam que cerca de um terço dos enfermeiros formados pelas universidades portuguesas, públicas e privadas, emigra, sendo a grande motivação para sair a falta de emprego, a ausência de perspetivas de progressão na carreira e desenvolvimento profissional e o melhor nível de remuneração salarial no país de destino. Segundo um inquérito realizado pela Ordem dos Enfermeiros, entre os que emigram, a maioria exercia a profissão em Portugal em períodos entre um a cinco anos, surgindo de seguida os recém-licenciados, com períodos de exercício da profissão inferiores a um ano. É manifesto o problema dos jovens enfermeiros desempregados ou recém-licenciados a exercerem atividades diferentes da sua qualificação, com desperdício do investimento na sua formação, havendo carência destes profissionais na saúde, no entanto, a crise e a contenção dos gastos públicos impõem limites ao seu recrutamento em Portugal.

Também o Bastonário da Ordem dos Médicos denuncia a crescente emigração destes profissionais em Portugal, sobretudo jovens, e a situação paradoxal: há falta de médicos em algumas especialidades e o Estado investe milhares de euros na sua formação, mas eles emigram principalmente para países mais desenvolvidos do centro e norte da Europa, mas também de outros continentes, como África. Em Moçambique, a procura de pessoal qualificado na medicina é grande, principalmente devido à importância de doenças como HIV/SIDA, malária, etc. O Banco Mundial constata a grande emigração qualificada e a fuga de cérebros no mundo lusófono: entre os 30 países com taxas mais elevadas de emigração da população qualificada em 2000 (países com mais de 5 milhões de habitantes), estão em 3. ${ }^{\circ}$ lugar Moçambique, em 7. ${ }^{\circ}$ Angola e em 21. ${ }^{\circ}$ Portugal (Ozden e Schiff, 2005). 
Entre os jovens portugueses qualificados que migraram para o Brasil depois de 2008, destaca-se, entre os entrevistados, a falta de perspetivas de futuro e de oportunidades para progredir em Portugal (Fracalossi e Ramos, 2013), o que reforça a ideia de que a estagnação económica e a instabilidade política e socioeconómica no país de origem, aumentam a propensão de emigrar (Taran et al., 2009).

Em Portugal, entre os jovens qualificados que emigram, destacamse as áreas da Medicina e Saúde, Engenharia, Economia, Gestão e Tecnologias de Informação. Por exemplo, as empresas moçambicanas tendem a contratar, para os seus quadros, trabalhadores qualificados com licenciatura ou diploma de pósgraduação noutros países. Inicialmente, eram oriundos dos países socialistas, mas, desde 1990, dominam os países ocidentais, entre eles Portugal, fornecendo profissionais de diferentes áreas que procuram melhores condições laborais (Costa, 2009).

O estudo de Fracalossi e Ramos (2013) destacou os seguintes fatores influenciadores do aumento da mobilidade dos jovens trabalhadores portugueses qualificados para o Brasil, depois do acentuar da crise: interesses pessoais de crescimento, desenvolvimento profissional e reconhecimento futuro da experiência internacional; questões económicas como falta de perspetivas e oportunidades em Portugal e crescimento económico do Brasil; redes de contactos, idioma e clima do Brasil; situação do mercado de trabalho de ambos os países, ou seja, o grande desemprego em Portugal e, inversamente, a oferta de emprego no Brasil.

As considerações profissionais aparecem essenciais na decisão de procurar emprego no estrangeiro, sendo referidos os fatores mais importantes relacionados com a carreira: experiência profissional internacional vista como uma mais-valia e um diferencial positivo para reconhecimento posterior; desenvolvimento da carreira com 
responsabilidades e oportunidades de adquirir conhecimentos e competências. Quanto às oportunidades de emprego na área específica de formação, metade dos entrevistados trabalhava na sua área de formação, em Portugal, quando decidiu emigrar para o Brasil, e os principais motivos de saída relacionam-se com a insegurança no emprego e a falta de valorização da carreira. Dos restantes, $30 \%$ procuraram no Brasil a primeira experiência de trabalho e $20 \%$ através de estágios profissionais, que originaram possibilidades de empregos. Os motivos de não ter a primeira experiência profissional em Portugal são a dificuldade de obter emprego na área de formação específica, sendo que apenas $20 \%$ dos entrevistados estavam desempregados no momento da emigração. Relativamente aos planos de futuro nos próximos cinco anos e às intenções de ficar ou não no Brasil, as respostas dividemse: $50 \%$ ficarão neste país, já estando a constituir família; $20 \%$ pensam daqui a cinco anos estar de volta a Portugal; apenas uma jovem retornou ao seu país, não conseguindo a integração laboral, por falta de visto, fazendo, contudo, planos de voltar ao Brasil logo que possível. E $20 \%$ dos entrevistados não têm a certeza do seu destino daqui a cinco anos.

\section{Integração laboral dos migrantes e sua desqualificação profissional}

A mobilidade e circulação dos conhecimentos, da cultura, da inovação e inteligência humana seguem em paralelo com algumas restrições à mobilidade humana. A Europa tem vindo a uniformizar as políticas relativas à população imigrante que acolhe no seu território, com tendência à imposição de maiores exigências aos fluxos de entrada e até criminalização dos mesmos. Apesar da necessidade de mão-de-obra específica por parte de países desenvolvidos, como a Alemanha, o recrutamento de migrantes qualificados em tempo de crise económica é cada vez mais seletivo 
em numerosos países (Canadá, Reino Unido, Espanha, Suíça, etc.) que colocam restrições para proteger os nacionais do desemprego e introduzem medidas para flexibilizar a seleção dos candidatos à imigração e para atrair investidores e empresários (Alemanha, Canadá, Reino Unido, Noruega, etc.).

A situação laboral dos imigrantes na Europa e países da OCDE deteriorou-se nos últimos anos e é visível no desemprego no país de acolhimento. Em média, o desemprego dos estrangeiros aumentou cinco pontos percentuais entre 2008 e 2012, em comparação com três pontos percentuais para os nascidos no país (OECD, 2013). Nos países da OCDE, a taxa de desemprego dos imigrantes passou de 8,1\% em 2008 para 12,9\% em 2012, contra um aumento de $5,4 \%$ a $8,7 \%$ para os autóctones. O desemprego de longa duração é grave em muitos países, estando em 2012 cerca de metade dos imigrantes desempregados à procura de um emprego há mais de um ano. O impacto foi mais forte entre os migrantes da América Latina e do Norte de África. Estes migrantes africanos, na Europa, registaram taxas de desemprego de 26,6\% em 2012. Os jovens imigrantes foram particularmente afetados pela crise, sendo as mulheres e os migrantes altamente qualificados menos atingidos do que os trabalhadores pouco qualificados. A discriminação dos imigrantes e dos seus filhos é uma realidade, enviando estes duas vezes mais candidaturas para obter uma entrevista de recrutamento do que as pessoas não imigrantes. Nas mulheres migrantes, a discriminação existe igualmente (Ramos, 2010). Para a OCDE (2013), a taxa de desemprego em Portugal para os homens nascidos neste país foi de $12,7 \%$ em 2011 e atingiu os $18 \%$ para os homens estrangeiros. Quanto às mulheres nascidas em Portugal a taxa de desemprego foi de $13,3 \%$, e de $15,9 \%$ para as que nasceram no estrangeiro. Segundo dados do Eurostat, o desemprego em Portugal entre imigrantes de fora da União Europeia (UE) foi o dobro do dos portugueses em 2012: a taxa de desemprego atingiu 15,6\% para os 
portugueses, 16,6\% para cidadãos de outro Estado-membro e 28,9\% para cidadãos de fora da UE.

Os níveis de formação e informação e as redes sociais são fatores importantes para o sucesso do migrante, que desenvolve cada vez mais estratégias de vida com múltiplas pertenças, culturas, identidades e nacionalidades (Ramos, 2011b). Trabalho, educação, competências linguísticas e multiculturais e dupla nacionalidade favorecem a integração e a participação civil nos países de acolhimento e de origem, aumentam a mobilidade e a participação efetiva dos migrantes qualificados no mercado de trabalho (Ramos e Gomes, 2007; Ramos et al., 2007; OECD, 2011).

Apesar destes progressos, a educação dos imigrantes nem sempre é valorizada nos países de acolhimento, verificando-se problemas de desqualificação profissional, desperdício de "cérebros", desigualdade de oportunidades e discriminação, constituindo não só uma perda de recursos humanos valiosos e de coesão social, mas comportando também riscos psicossociais para os próprios migrantes, nomeadamente mulheres (Marin-Avellan e Mollard, 2011). Nos países da OCDE, pelo menos $25 \%$ dos imigrantes qualificados eram inativos, desempregados ou relegados para atividades inferiores às suas qualificações, e o salário médio de um imigrante era cerca de $20 \%$ mais baixo do que o de um nacional (Ramos, 2010). Um relatório do Eurostat sobre migrações na Europa a 27 países (2011) indica que $25 \%$ dos estrangeiros residentes em Portugal são excessivamente qualificados para o trabalho que exercem, enquanto entre os portugueses a taxa é de $14 \%$.

\section{Políticas de valorização de competências e reconhecimento de qualificações dos migrantes}

O bem-estar e o modo como os indivíduos se adaptam ao novo contexto de trabalho internacional têm grande influência sobre o 
seu desempenho, sendo essencial um equilíbrio saudável entre a vida familiar e profissional, através do uso efetivo de políticas de expatriação congruentes com esse objetivo (Meyskens et al, 2009). De acordo com Downling (2008), os falhanços internacionais estão muitas vezes relacionados com a má gestão dos recursos humanos. Assim, a formação e o desenvolvimento das competências dos expatriados são prioritários para a gestão internacional de recursos humanos. No mercado de trabalho global, o potencial de recursos humanos qualificados com múltiplas valências linguísticas e culturais, capazes de trabalhar em diferentes ambientes e em constante mobilidade, é um fator de competitividade (Ramos, 2013).

Dificuldades de transferência do capital humano, problemas decorrentes do reconhecimento de diplomas e qualificações e questões linguísticas associadas podem ser causadores de uma mobilidade descendente após a migração, gerando um desperdício de capital humano do migrante nos dois extremos da cadeia migratória.

As novas realidades e perfis migratórios exigem novas competências das instituições e das políticas públicas. As políticas de integração e os fundos públicos consagrados variam substancialmente de um país para outro, alguns continuam a investir recursos significativos em medidas de integração, enquanto outros reduziram substancialmente esses valores devido à recessão económica e às contenções orçamentais. Há necessidade de apoio à inserção laboral dos migrantes, de modo a evitar efeitos de exclusão, nomeadamente entre os migrantes jovens e os filhos de imigrantes nascidos no país de acolhimento, mas também dos mais qualificados, incluindo homens e mulheres.

Sendo a educação internacional um fator-chave para a prosperidade, nomeadamente nas áreas da inovação, comércio, desenvolvimento do capital humano e do mercado de trabalho, 
alguns países, como Portugal, têm concentrado esforços na adoção de estratégias de cooperação nesta área do conhecimento. Os benefícios do impacto económico, aliado às potencialidades das redes académicas e científicas, por exemplo de ex-alunos quando regressam aos seus países de origem, não podem ser desvalorizados.

Portugal introduziu políticas de incentivo à internacionalização do saber, quando os países vivem num contexto de competição global pelo talento:

- Aprovação pelo governo português do Estatuto do Estudante Internacional.

- Atração de mão-de-obra altamente qualificada, através da lei $n^{\circ}$ 23/2007, que simplificou o regime de concessão de autorização de residência a estudantes de ensino superior e a investigadores.

- Introdução do Programa Investigador FCT (Fundação para a Ciência e a Tecnologia) para atrair talentos estrangeiros e portugueses no exterior, cujo objetivo é apoiar o recrutamento pelos centros de investigação nacionais dos melhores investigadores, de qualquer nacionalidade, internacionalmente competitivos e com capacidade comprovada para desenvolver investigação inovadora. Está a funcionar desde 2012 e oferece uma remuneração competitiva, sob a forma de um contrato de trabalho, por um período de cinco anos.

- Alteração da lei no 23/2007 de 4 de Julho pela lei no 29/2012 de 9 de Agosto, introduzindo uma nova modalidade de visto de residência, o cartão azul UE, o qual habilita um nacional de país terceiro a residir e a exercer em território português, uma atividade profissional subordinada altamente qualificada. 


\section{Proposições e considerações finais}

A mobilidade humana constitui um dos motores fundamentais das profundas transformações nas dinâmicas socioeconómicas contemporâneas, reconfigurando as concepções de educação, trabalho, cidadania e cooperação. $\mathrm{O}$ incremento internacional científico, cultural e económico exige gerir as competências e a interculturalidade, face ao aumento de migrantes qualificados e empreendedores, e impõe algumas prioridades:

- Agilizar o reconhecimento, certificação e validação de competências adquiridas no estrangeiro e adequar formação e emprego dos migrantes nos países de acolhimento e de origem;

- Desenvolver redes de cooperação científica e cultural entre países de imigração e de emigração;

- Facilitar a mobilidade internacional e a circulação migratória e promover múltiplas cidadanias e pertenças;

- Incentivar o desenvolvimento de um ambiente académico mais cosmopolita e intercultural, facilitando o ingresso e a mobilidade discente e docente de origem estrangeira;

- Lutar contra as desigualdades e discriminações, promovendo a gestão intercultural, fator de prevenção da discriminação e de coesão social.

Posto isto, novos paradigmas das migrações apelam à cooperação e ao fortalecimento do co-desenvolvimento entre países de imigração e de emigração para potenciar os efeitos positivos das migrações, pressupondo a partilha mais equitativa entre países de acolhimento e de origem (Taran et al., 2009). É importante analisar as intersecções entre mobilidade, imobilidade e relações estratégicas entre diferentes regiões, à escala global. A globalização torna cada vez mais necessária a transição do "controle migratório" para a "gestão migratória", no atual contexto de crise, formação, transformação e intensificação dos movimentos. Importa reforçar o 
impacto da mobilidade qualificada na cultura, educação, economia, internacionalização e desenvolvimento dos países de origem e de acolhimento. Fenómeno social complexo, a mobilidade não se restringe à deslocação dos seres humanos no espaço físico através das migrações. Ela comporta também alterações societais na estrutura e hierarquia social e na forma como os indivíduos se integram e contribuem com conhecimentos e trabalho para a construção de novas realidades. 


\section{Referências}

Abada, T.; Hou, F.; Lu, Y. (2014). Choice or necessity: do immigrants and their children choose self-employment for the same reasons? Work, Employment \& Society, 28(1), 78-94.

Beine, M.; Docquier, F.; Rapoport, H. (2008). Brain drain and human capital formation in developing countries: winners and losers. The Economic Journal, 118 (528), 631-652.

Berset, A. et al. (2000). Main-d'œuvre étrangère et diversité des compétences. Paris: L'Harmattan.

Brettell, C. (2007). Immigrant women in small business: biographies of becoming entrepreneurs. In L.-P. Dana (Ed.) Handbook of research on ethnic minority entrepreneurship (pp. 8398). Cheltenham: Edward Elgar.

Castles, S. (2010). Understanding global migration: A social transformation perspective. Journal of Ethnic and Migration Studies, 36(10), 1565-1586.

Chiswick, B. R. (ed.) (2011). High-skilled immigration in a global labor market. Washington, DC: AEI Press.

Costa, A. B. (2009). Emigração de quadros, formação superior e desenvolvimento: o caso de Moçambique. Pro-posições, v. 20, n. 1 (58), 127-145.

Delicado, A.; Alves, N. A. (2013). "Fugas de cérebros', 'tetos de vidro' e 'fugas na canalização': mulheres, ciência e mobilidade. E. Araújo; M. Fontes; S. Bento (Coord.) Para um Debate sobre Mobilidade e Fuga de Cérebros (pp. 8-31). Braga, Centro de Estudos de Comunicação e Sociedade.

Docquier, F.; Marfouk, A. (2006). International migration by education attainment, 1990-2000. In C. Ozden; M. Schiff (Eds.) International migration, remittances and the brain drain (pp. 151199). Washington: World Bank and Palgrave Macmillan.

Docquier, F.; Marfouk, A.; Salomone, S.; Sekkat, K. (2012). Are Skilled Women More Migratory than Skilled Men? World Development, 40 (2), 251-265.

Dowling, P. (2008). International human resource management: Managing people in a multinational context (5th ed.). South Melbourne: Thomson.

Dreher, A.; Poutvaara, P. (2005). Student flows and migration: an empirical analysis. CESIFO Working Paper no 1490. 
Dumont, J.; Martin, J. P.; Spielvogel, G. (2007). Women on the move: The neglected gender dimension of the brain drain. IZA DP $\mathrm{N}^{\circ} 2090$.

Enderwick, P.; Tung, R.; Chung, H. (2011). Immigrant effects and international business activity: an overview. Journal of Asia Business Studies, 5 (1), 6-22.

Falquet, J.; Hirata, H.; Kergoat, D. et al. (Org.) (2010). Le sexe de la mondialisation. Genre, classe, race et division du travail. Paris: Presses de Sciences Po.

Fracalossi, C.; Ramos, M. C. (2013). O Brasil na rota da imigração e da mobilidade dos trabalhadores portugueses na atualidade. In Jornadas sobre Grandes Problemáticas do Espaço Europeu. The Overarching Issues of the European Space. FEP e FLUP, Universidade do Porto.

Gaillard, A.-M.; Gaillard, J. (1999). Les enjeux des migrations scientifiques internationales. De la quête du savoir à la circulation des compétences. Paris: L'Harmattan.

Godinho, V. M. (1978). L'émigration portugaise (XVe-XXe siècles). Une constante structurelle et les réponses au changement du monde. Revista de História Económica e Social, 1, 5-32.

Grignon, M.; Owusu, Y.; Sweetman, A. (2012). The international migration of health professionals, IZA DP $\mathrm{n}^{\circ} 6517$.

Kahanec, M. (2012). Skilled labor flows: lessons from the European Union, IZA Research Report, $\mathrm{n}^{\circ} 9$.

Kloosterman, R. ; Rath, J. (2010). Shifting Landscapes of Immigrant Entrepreneurship. In OECD. Open for Business. Migrant Entrepreneurship in OECD Countries (pp. 101-123). Paris: OECD.

Kloosterman, R.; Rath, J. (2010). Immigrant entrepreneurship in advanced economies. Mixed embeddedness further explored. Journal of Ethnic and Migratons Studies, vol. 27, 189-201.

Kofman, E. (2000). The invisibility of skilled female migrants and gender relations in studies of skilled migration in Europe. International Journal of Population Geography, 6 (1), 45-49.

Korpi, M.; Hedberg, Ch.; Pettersson, K. (2013). Immigrant women and entrepreneurship: a study of the health care sector in Sweden, 
2002-2006, Working Paper 2013:1, The Stockholm University Linnaeus, Center for Integration Studies.

Levitt, P. (1998). Social Remittances: Migration Driven LocalLevel Forms of Cultural Diffusion. International Migration Review, 32 (4), 926-948.

Malheiros, J.; Padilha, B. (Coord.) (2010). Mulheres imigrantes empreendedoras. Lisboa: CIG.

Marin-Avellan, L. E. ; Mollard, B. (2011). L'impact psychosocial du sous-emploi sur la vie des femmes migrantes qualifiées travaillant à Genève (Suisse). Genève: OIM.

Meyskens, M. et al. (2009). The paradox of international talent: alternative forms of international assignments. The International Journal of Human Resource Management. 20 (6), 1439-1450.

OCDE (2008). Attirer les talents: Les travailleurs hautement qualifiés au cour de la concurrence internationale. The Global Competition for Talent: Mobility of the Highly Skilled. Paris: OCDE.

OCDE (2010). Les migrations internationales des personnels de santé. Paris: OCDE.

OECD (2010). Open for business. Migrant entrepreneurship in OECD Countries. Paris: OECD.

OECD (2011). Naturalisation: a passport for the better integration of immigrants? Paris: OECD.

OECD (2011, 2012, 2013). International Migration Outlook. Paris: OECD.

OECD (2012). Untapped skills: realising the potential of immigrants students. Paris: OECD.

Ozden, C. ; Schiff, M. (Eds.) (2005). International migration, remittances and the brain drain, Washington: World Bank and Palgrave Macmillan.

Panayiotopoulos, P. (2010). Ethnicity, migration and enterprise. Basingstoke: Palgrave Macmillan.

Poot, J.; Roskruge, M. (2013). Internationalisation of education and returns in the labour market. IZA DP $\mathrm{n}^{\circ} 7696$. 
Ramos, M. C. P. (2007). Imigração, desenvolvimento e competitividade em Portugal. Revista Economia e Sociologia, $\mathrm{n}^{\circ}$ $84,2 .^{\circ}$ semestre, $71-108$.

Ramos, M.; Gomes, M. (2007). Dual citizenship, governance and education: the situation in Portugal. In D. Kalekin-Fishman; P. Pitkanen (Eds.) Dual citizenship as a challenge to European Nation-States (pp. 171-211). Rotterdam: Sense Publishers.

Ramos, M. et al. (2007). Multiple Citizenship. Case-Studies Among Individual Citizens in Portugal. In P. Pitkanen; D. KalekinFishman (Eds.) Multiple State Membership and Citizenship in the Era of Transnational Migration (pp. 41-65). Rotterdam: Sense Publishers.

Ramos, M. C. P. (2008). Desafios à Europa Social no Contexto da Globalização - Gestão da Diversidade e da Educação nas sociedades multiculturais e do conhecimento. In N. Ramos (Org.) Educação, Interculturalidade e Cidadania (pp. 6-29). Bucareste: Milena Press.

Ramos, M. C. P. (2009). Mulheres portuguesas na diáspora Inserção laboral e papel nas redes sociais. In L. Seabra; A. Espadinha (Orgs.) A vez e a voz da mulher portuguesa na diáspora (pp. 301-326). Macau: Universidade de Macau.

Ramos, M. C. P. (2010). Migrações e género - Trabalho, empreendedorismo e discriminações. In Seminário Internacional Fazendo Género 9 - Diásporas, Diversidades, Deslocamentos, Florianópolis, UFSC, 23-26/08/2010 (http://www.fazendogenero.ufsc.br/9/)1278297633_ARQUIVO_ComunicacaoFl orianopolisMCPR(1).pdf

Ramos, M. C. P. (2011a). Migrações internacionais e género dinâmicas de participação das mulheres portuguesas imigrantes. In R. Boschilia; M. L. Andreazza (Orgs.) Portuguesas na diáspora: histórias e sensibilidades (pp. 137-160). Curitiba: UFPR.

Ramos, M. C. P. (2011b). Mondialisation, Citoyennetés, Cultures. Crossing boundaries in culture and communication, 2 (2), 85-95.

Ramos, M. C. P. (2012a). Trabalho e empreendedorismo social da mulher portuguesa na diáspora. In M. M. Aguiar; M. G. S. Guedes (Orgs.) Encontro Mundial de Mulheres Portuguesas na Diáspora (pp. 22-26). Espinho: ed. Mulher Migrante.

Ramos, M. C. P. (2012b). Migrações e dinâmicas associativas e culturais. In N. Ramos; M. Marujo.; A. Baptista (Orgs.) A voz dos avós. Migração, Memória e Património Cultural (pp. 285-309). Coimbra: Ed. Gráfica de Coimbra/Fundação Pro Dignitate. 
Ramos, M. C. P. (2013). Globalização e Multiculturalismo. Revista Eletrónica Inter-Legere "Políticas públicas, teorias e experiências", 13, Jul/Dez, 75-101. www.cchla.ufrn.br/interlegere

Ramos, M. C.; Deaconu, A.; Radu, C. (2013). Brain drain of health care professionals - can we manage the process? In Proceedings of the 7 th International Management Conference "New Management for the New Economy", 7th-8th november, Bucharest, 149-155.

Ramos, M. C. P. (2014). Mobility, Internationalisation, Higher Education: European Challenges. In A. Dima (Coord.) Trends in European Higher Education Convergence (pp. 44-61). IGI Global, Hershey, PA, USA.

Robertson, S. (2013). Transnational student - migrants and the state: the education-migration nexus. Basingstoke: Palgrave Macmillan.

Sobral, M. N.; Ramos, N. (2012). Processo de Bolonha e internacionalização do ensino superior. Revista Tempos e Espaços em Educação, UFS, nº 8, 107-115.

Taran, P.; Ivakhnyuk, I.; Ramos, M. C. P.; Tanner, A. (2009). Economic migration, social cohesion and development: an integrated approach / Migrations économiques, cohesion sociale et développement: vers une approche intégrée. Strasbourg: Conseil de l'Europe.

Universidade do Porto (UP) (2014). Relatório de Internacionalização da Universidade do Porto 2012/2013, Porto: UP.

Weinberg, B. A. (2011). Developing science: Scientific performance and brain drains in the developing world. Journal of Development Economics, 95(1), 95-104. 